\title{
Effect of Accumulative Roll Bonding of an AZ31 Alloy on the Microstructure and Tensile Stress
}

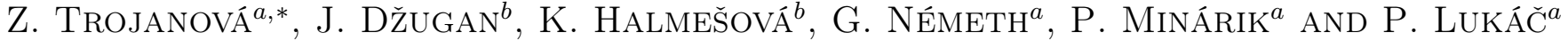 \\ ${ }^{a}$ Charles University Prague, Faculty of Mathematics and Physics, Ke Karlovu 5, CZ-121 16 Praha 2, Czech Republic \\ ${ }^{b}$ Comtes FHT, Dobřany, Průmyslová 996, CZ-334 41 Dobřany, Czech Republic
}

\begin{abstract}
Microstructure and texture of magnesium alloy AZ31 sheets subjected to accumulative roll bonding (ARB) were studied after 1 and 2 passes through the rolling mill. Sheets after the ARB process exhibited a very fine grain structure and significant basal texture. Tensile experiments were performed at room temperature. Distinctive planar anisotropy of mechanical properties was estimated. This anisotropy is explained by the slip crystallography and twinning.
\end{abstract}

DOI: 10.12693 /APhysPolA.134.863

PACS/topics: 61.72.Mm; 62.20.F-; 81.05.Bx

\section{Introduction}

The mechanical behaviour of magnesium alloys with their high specific strength is significantly affected by their microstructure and temperature. It is well known that the grain size is an important microstructural parameter influencing the deformation behaviour of the polycrystals. The deformation mechanisms in magnesium were investigated in many cases [1]. It has been reported in the literature that the yield strength increases with decreasing grain size through the Hall-Petch relationship. The grain refinement can be obtained when the material is subjected to severe plastic deformation (SPD) [2]. Among different SPD techniques, accumulative roll bonding is an effective and inexpensive method for grain refinement and improvement of mechanical properties $[2,3]$. This processing method was successfully used to manufacture ultra-fine grained $\mathrm{Al}$ alloys $[4,5]$. Application of ARB technology is not so easy in the case of $\mathrm{Mg}$ alloys because of low plasticity of these materials exhibiting hexagonal close packed structure. Increasing $\mathrm{Al}$ content increases strength in $\mathrm{Mg}-\mathrm{Al}-$ Zn alloys and decreases strain to fracture. AZ31 alloy with relatively low $\mathrm{Al}$ content is a suitable alloy for the sheets fabrication and also for accumulative roll bonding. Mechanical properties of AZ31 sheets exhibit a significant plastic planar anisotropy. Offset yield strength (OYS) and ultimate tensile strength (UTS) estimated in the rolling direction are lower than those estimated in the transversal direction $[6,7]$. The objective of the present study is to estimate the effect of accumulative roll bonding on microstructure and mechanical behaviour of an AZ31 alloy.

\section{Experimental}

Commercially available magnesium alloy AZ31 was used in this study. The chemical composition of the

*corresponding author; e-mail: ztrojan@met.mff.cuni.cz alloy is introduced in Table I. In the accumulative roll bonding (ARB) process, two layers of a material are purified and subsequently joined together by rolling. The initial sheet thickness was $2 \mathrm{~mm}$ and the rolling reduction was $50 \%$ in each pass. The rolling process was performed at a temperature of $400^{\circ} \mathrm{C}$. One and two passes through the rolling mill were applied. Orientation to the rolling direction (RD) in the sheet sample is depicted in Fig. 1. The sheet surface is the A plane, B plane is parallel to the $\mathrm{RD}$ while the $\mathrm{C}$ plane is perpendicular. Sample's microstructure was studied using a light microscope Olympus. The texture analysis was performed in a FEI Quanta 200 FX scanning electron microscope equipped with EDAX EBSD camera. Tensile tests were performed at room temperature in an INSTRON 5486 machine with an initial strain rate in the order $10^{-3} \mathrm{~s}^{-1}$. Samples are designated as ARB_0 (as received sheet), ARB_1 (after one rolling pass) and ARB_2 (after two passes in the rolling mill). Samples were cut from sheets so that the tensile axis was either parallel $(\mathrm{L})$ or perpendicular $(\mathrm{T})$ to the rolling direction.

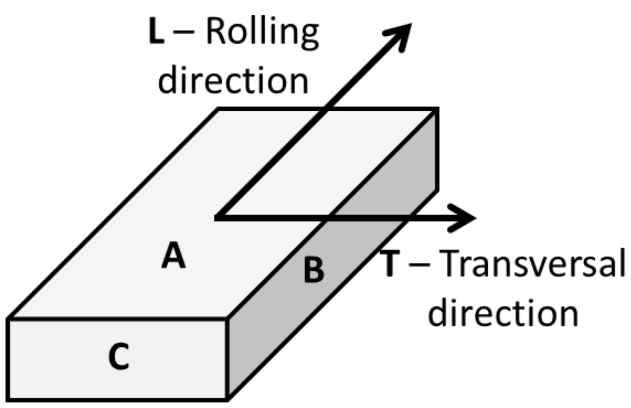

Fig. 1. Orientation of the three sample planes with respect to the RD.

TABLE I

Chemical composition of the material (in weight \%)

\begin{tabular}{c|c|c|c|c|c|c|c}
\hline \hline Material & $\mathrm{Al}$ & $\mathrm{Zn}$ & $\mathrm{Mn}$ & $\mathrm{Si}$ & $\mathrm{Fe}$ & $\mathrm{Ce}$ & $\mathrm{Mg}$ \\
\hline AZ31_RS & 3.2 & 1.3 & 0.4 & 0.015 & 0.03 & 0.06 & Bal.
\end{tabular}




\section{Results and discussion}

OYS and UTS measured for L and T samples at room temperature are given in Table II. It can be seen that the TYS increases with increasing number of passes for both orientations. The same is valid for the UTS. Comparing both orientations it is obvious that the characteristic stresses are higher in the L orientation. This result does not agree with results of other authors who estimated lower deformation stresses in the rolling direction $[6,7]$. The microstructure of samples was analysed on three different planes as it is indicated in Fig. 1. Light micrographs of the as received sheet are reported in Fig. 2.
Characteristic stresses estimated in the

TABLE II rolling (L) and transversal $(\mathrm{T})$ directions

\begin{tabular}{c|c|c|c|c}
\hline \hline $\begin{array}{c}\text { No. of } \\
\text { passes }\end{array}$ & $\begin{array}{c}\text { OYS(L) } \\
{[\mathrm{MPa}]}\end{array}$ & $\begin{array}{c}\text { OYS(T) } \\
{[\mathrm{MPa}]}\end{array}$ & $\begin{array}{c}\text { UTS(L) } \\
{[\mathrm{MPa}]}\end{array}$ & $\begin{array}{c}\text { UTS(T) } \\
{[\mathrm{MPa}]}\end{array}$ \\
\hline 0 & 162.5 & 85.0 & 307.0 & 297.0 \\
1 & 223.0 & 172.4 & 344.9 & 365.6 \\
2 & 227.0 & 212.0 & 356.6 & 370.0
\end{tabular}

Typical feature of the microstructure taken from plane A are bigger grains surrounded with smaller ones. Twins are visible in planes B and C. Dark particles containing $\mathrm{Al}$ and $\mathrm{Mn}$ are very probably $\mathrm{Al}_{8} \mathrm{Mn}_{5}$ observed already in AZ31 alloy $[8,9]$.
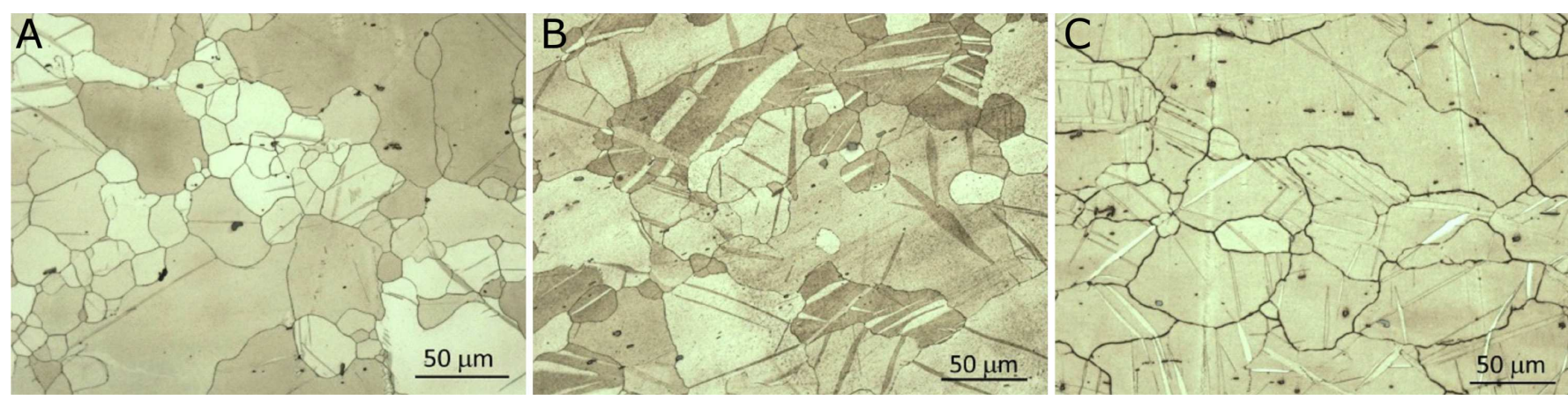

Fig. 2. Light micrographs of as received sheet taken from A, B and C planes defined in Fig. 1.
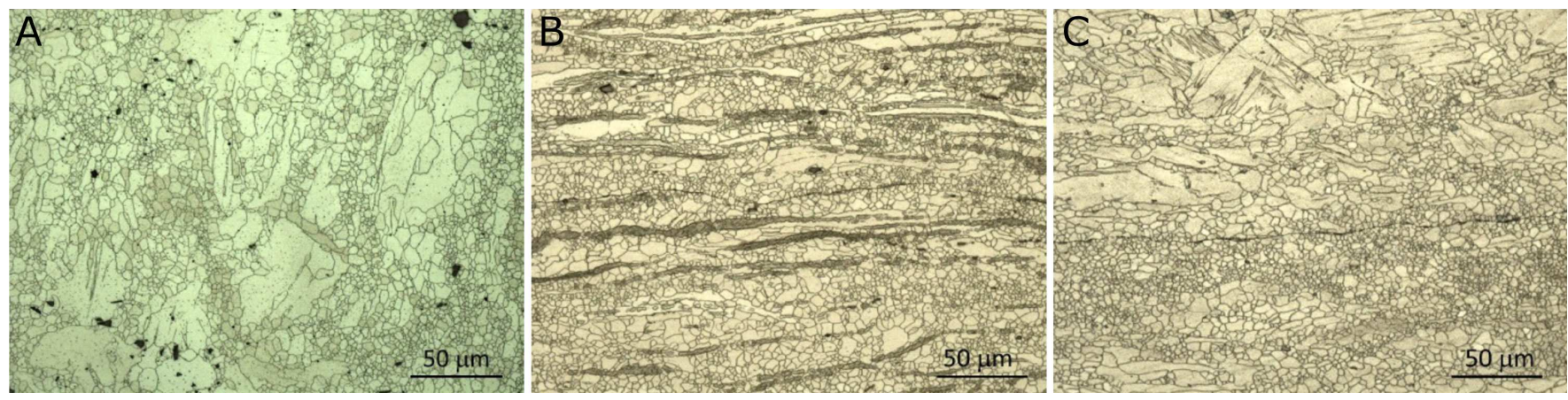

Fig. 3. Light micrographs of the ARB_1 sample after one rolling pass taken from A, B and C planes.
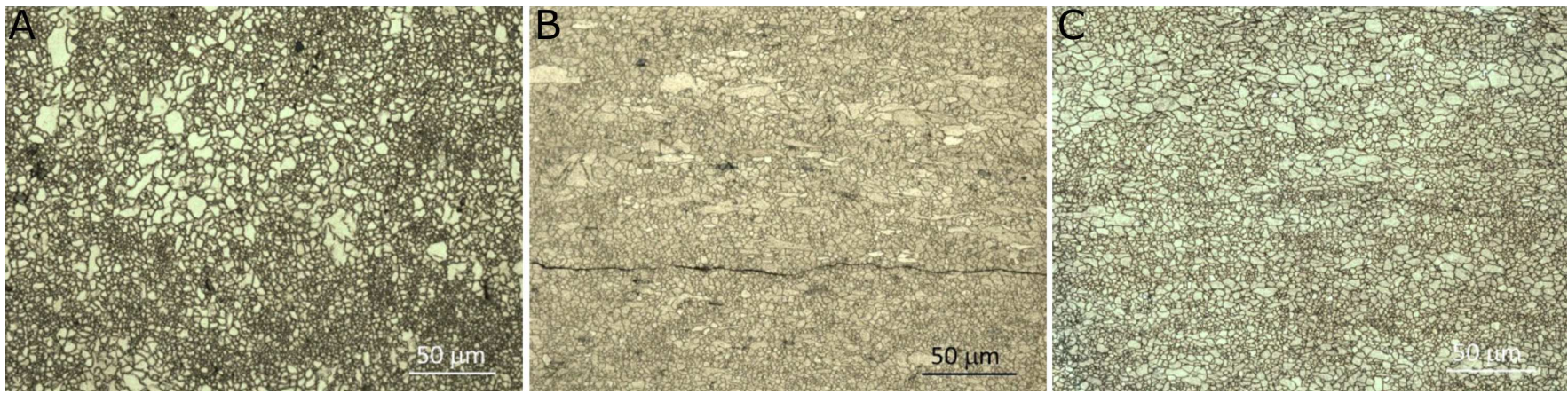

Fig. 4. Light micrographs of the ARB_2 sample after two rolling passes taken from A, B and C planes. 
In the ARB 1 sample, bimodal grain size distribution was observed. Coarse grains visible in Fig. 3 coexist with very small grains newly formed during dynamic recrystallization. Good bonding may be achieved as a result of dynamic recrystallization (DRX) [10]. An interesting view on deformed microstructure provides the micrograph taken from the plane B. The shear zones containing very small uniaxial grains are nearly parallel to the sheet surface. Ion et al. showed that these shear zones are formed via dynamic recrystallization [11]. This mechanism entails dynamic polygonisation of rotated grain boundary regions. Deformation within the shear zones is realised by the dislocation motion predominantly in basal planes. The stored energy is released by the dynamic recovery and recrystallization. A bonding between both sheet parts is visible in the plane $\mathrm{C}$. This bonding is also a result of DRX at an original bonding line. The microstructure of the ARB_2 sample is shown in Fig. 4. (a)

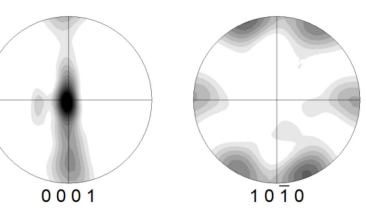

(c)

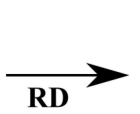

(b)
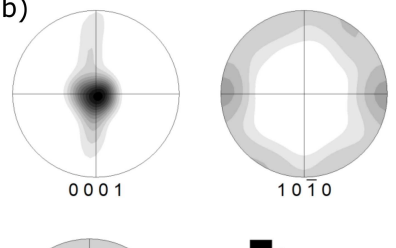

is the Hall Petch strengthening. Planar plastic anisotropy was observed in magnesium alloys [12]. This anisotropy was related to the texture which is present in rolled sheets. Crystallographic texture was improved during ARB process in the first and second rolling pass. The texture can be characterised as a fiber texture with the $c$ axis perpendicular to the sheet surface. The distribution of basal poles shows a basal pole tilted away from the normal direction towards the transverse direction, as can be seen in Fig. 5. Such type of the texture with the angular distribution of the basal poles broader in the transversal direction was observed in $\mathrm{Mg}$ alloys containing rare earths or Ca [13]. Mackenzie and Pekguleryuz have reported that even small (0.3wt.\%) Ce addition changes the texture of $\mathrm{Mg}-1 \mathrm{Zn}$ alloy so that the splitting of the basal poles is in the transversal direction [14]. In alloys with a such special texture, the OYS is higher in the rolling direction than in the transversal direction [12]; similarly to results presented in this paper. The micrograph of the Vickers pyramid imprint was oriented so that the diagonals were oriented in rolling $(\mathrm{L})$ or transversal $(\mathrm{T})$ directions (see Fig. 6). Formation of twins is apparent in the $\mathrm{T}$ direction. Balík et al. studied in plane plastic deformation in the AZ31 sheets [7]. They found that the plastic deformation starts at very low stresses by the movement of dislocations in the basal planes. Further steps of deformation are provided by the combined slip in two prismatic planes. On the other hand mechanical twinning is the deciding process in the $\mathrm{T}$ direction at least at the beginning of straining. The twining activity can be connected with the texture asymmetry around the normal direction with respect to the sheet surface. Twinning as a deformation mode may operate only if the c-axis and the tensile stress axis are sufficiently close to each other. This geometrical condition is fulfilled only for the $\mathrm{T}$ direction.

\section{Conclusions}

Based on experimental results, the following conclusions may be drawn:

- The homogeneity of the sheet microstructure increases with increasing number of passes.

- Strong basal texture developed during ARB process.

- Planar plastic anisotropy was observed.

- Characteristic stresses increase with increasing number of passes.

- Different deformation mechanisms operate during tensile deformation in the rolling and transversal directions.

\section{Acknowledgments}

Uniform microstructure containing very small grains planes. Bonding between both sheet parts is well visible in the plane $\mathrm{B}$, partially also in $\mathrm{C}$. The grain size decreased from the original value of $32 \mu \mathrm{m}$ down to $5 \mu \mathrm{m}$. An increase of the OYS with increasing number of passes
This work was realised with the support of the Grant Agency of the Czech Republic under the contract 107$15 / 11879$ S. 


\section{References}

[1] R.S. Agnew, Deformation mechanisms in magnesium alloys. In: Advances in wrought magnesium alloys, Eds. C. Bettles, M. Barnett, Woodhead Publishing, Oxford 2012.

[2] Y. Estrin, A. Vinogradov, Acta Mater. 61, 782 (2013).

[3] F. Schwarz, C. Eilers, L. Krüger, Mater. Characterization 105, 144 (2015).

[4] W.-Z. Chen, W.-C. Zhang, Y.-D. Qiao, Q. Miao, E.D. Wang, J. Alloys Compd. 665, 13 (2016).

[5] J.A. del Valle, M.T. Pérez-Prado, O.A. Ruano, Mater. Sci. Eng. A, 410-411, 353 (2005).

[6] J. Balík, P. Lukáč, R. Kužel, Acta Phys. Pol. A 122, 435 (2012).

[7] J. Balík, P. Dobroň, F. Chmelík, R. Kužel, D. Drozdenko, J. Bohlen, D. Letzig, P. Lukáč, Int. J. Plast. 76166 (2016).
[8] S. Pawar, X. Zhou, T. Hashimoto, G.E. Thompson, G. Scamans, Z. Fan, J. Alloys Compd. 628, 195 (2015).

[9] M. Ohno, D. Mirkovic, R, Schmid-Fetzer, Acta Mater. 54, 3883 (2006).

[10] Q.F. Wang, X.P. Xiao, J. Hu, W.W. Xu, X.Q. Zhao, J.S. Zhao, J. Iron Steel Res. Int. 14, 167 (2007).

[11] S.E. Ion, F.J. Homphreys, H.S. White, Acta Metall. 301909 (1982).

[12] P. Dobroň, J. Balík, F. Chmelík, K. Illková, J. Bohlen, D. Letzig, P. Lukáč, J. Alloys Compd. 588628 (2014).

[13] J. Bohlen, M.R. Nürnberg, J.W. Senn, D. Letzig, S.R. Agnew, Acta mater. 55, 2101 (2007).

[14] L.W.F. Mackenzie, M.O. Pekguleryuz, Scripta Mater. 59, 665 (2008). 